\title{
Parthian settlement patterns in the central Zagros region of western Iran
}

\author{
Yaghoub Mohammadifar ${ }^{1}$, Kamal Aldin Niknami ${ }^{2, ~ * ~}$ \\ ${ }^{1} \mathrm{Bu}$. Ali Sina University, Hamedan, Iran \\ ${ }^{2}$ University of Tehran, Iran \\ Email address: \\ yamohammadi@yahoo.com(Y. Mohammadifar); kniknami@ut.ac.ir(K. A. Niknami)
}

\section{To cite this article:}

Yaghoub Mohammadifar, Kamal Aldin Niknami. Parthian Settlement Patterns in the Central Zagros Region of Western Iran. International Journal of Archaeology. Vol. 1, No. 1, 2013, pp.6-12.doi: 10.11648/j.ija.20130101.12

\begin{abstract}
The study area in this research lies in the region of the Central Zagros, western Iran. An archaeological survey was conducted and approximately 340 Parthian (ca 250 B.C.225A.D.) archaeological sites were discovered and recorded. The aim of the project was to develop a set of simple procedures that could be widely used to build basic models of site location and settlement patterns of Parthian sites. Two methodological issues are addressed in this paper: (1) technical aspects regarding basic methods of data collection and GISbased processing and analysis; and (2) modeling archaeological site distribution patterns using the available archaeological and environmental data. In order to explore further the location of archaeological sites, a Geographical Information System (GIS) was developed combining all information from the recent survey of the area. The incorporation of this information into a GIS resulted in a digital archive of the survey area that enables the user to simultaneously visualize and analyze all data within their original spatial contexts making it possible to develop a more comprehensive investigation into the sites. The digital database was developed to synthesize information on site type, size, dating, and function. These data are subsequently used to address issues concerning changing settlement patterns in the study area. We suggest that the settlement patterns are, to a large extent, directly shaped by wideranging cultural needs which offer a strategic point for functional interpretation of the Parthian culture.
\end{abstract}

Keywords: Parthian, Central Zagros, Iran, Settlement Patterns, GIS, Digital Archive

\section{Introduction}

Until only a few decades ago, archaeological surveys were considered as only a preliminary phase of investigations in order to determine sites for excavation, and served as a means for archaeologists to pinpoint the best locations for long-term explorations [1]. However in the last few decades, archaeological survey has become an independent research method, and its scientific approach fills a large part of the existing gap in archaeological explorations. In scientific surveys, archaeologists are concerned with more than simply the identification of areas to be studied; the primary objectives include understanding variations and patterns in the distribution of human activities in specific places, as well as determining the relationship between humans and their environment as well as the available natural resources.

\section{The Research Problem}

The Parthian period (ca 250 B.C.225 A.D.), although one of the most important in the pre-Islamic eras[2], received little attention until the early 20 th century, when orientalists and archaeologists launched investigations, gradually exploring a number of cities and sites dating to this era. The areas investigated stretched westward from Central Asia to Syria. The objectives of this long-term research project are to investigate the Parthian economic and social practices across the Central Zagros region based on archaeological data, and to identify the relationship between the settlement patterns and the natural and mineral resources.

\section{The Geography of the Central Zagros Region}

In considering political borders, the Central Zagros region includes part of Hamadan province to the east, and large areas in Kermanshahprovince to the center and west. 
Northwards, it partly includes Kurdistan province and southwards includes Lorestan and Ilam provinces. The phrase "Central Zagros" was adopted by archaeologists studying the pre-history of Iran,primarily American and Canadian researchers [3]. Some assume that the region extends beyond Kermanshah, Kurdistan, Hamadan, Ilam, and Lorestan provinces, whilst Young considers it to be centered in Kermanshah and limited by the surrounding valleys[4]. In this study it is considered to be modeling archaeological site distribution patterns using the available archaeological and environmental data.

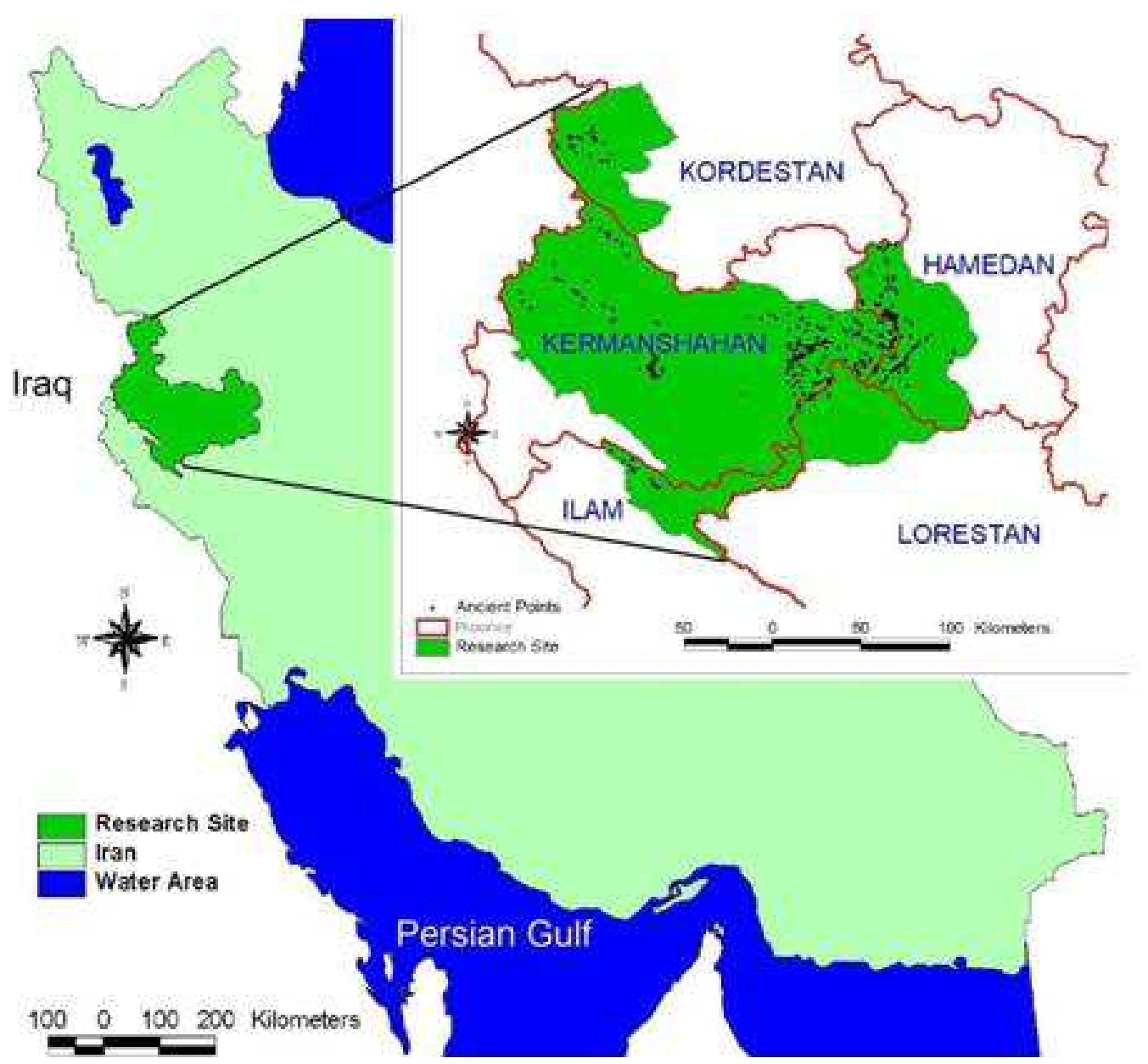

Fig 1. Map of Iran and location of study areas

\section{The Research Data and Procedures}

The data were acquired through an archaeological survey in the Central Zagros region by potterycollectionand accurate sampling. Eleven townships in the provinces of Kermanshah, Hamadan, Kurdistan, and Ilam,including Kangavar, Sahneh, Harsin, Kermanshah, Assadabad, Tuyserkan, Malayer, Marivan, and ShirvanChardaval (Hulilan), were selected through locational analysis, with the aim of identifying the settlement patterns and the regional conditions during the Parthian period in this geographical area. Overall, 623 sites were identified, of which 340 mounds and areas dating to the Parthian period were described,and data was gathered from those sites to create a databankfor GIS analysis. The total survey area was approximately 11,000 square kilometers, covering the Zagros plains and the surrounding mountains(fig. 1).

\subsection{The Pottery Data Analysis}

Analysis of the number and size of sites datable by ceramics suggests that during the Achaemenid period,regionalvillages were less densely populated, with limited crop production, than the Parthian and Seleucid eras, when the population grew larger [5][6]. The Achaemenid periodremains largely vague in the studies conducted over western Iran to date[7]. In the Central Zagros region, the Parthian period can be clearly identified by the emergence of several distinctive types of pottery, including characteristic "Clinky" pottery. With regard to settlement density, the Kangavar Plain [8] and Chamchamal Plain [9] have the highest densities. Inthe Malayerplain a large number of sites dating back to the 
Iron Age III were recorded, but the transition of the Iron Age III into the Achaemenid and Parthian periods was not recognized in this area[6].

Settlement patterns in west and southwest Iran from the beginning of theAchaemenid perioduntil the early Parthian periodare poorly understood as the number of the sites representing this period is very short. The only practical way to find answers for these questions, and to establish a continuous chronology from the Achaemenid period through to the Parthian period in west Iran is to study areas which have continuous occupation between these periods. Fortunately, this research has identified sixteen locations characterized by such continuity in the Central Zagros region, encompassing the Iron Age III through to the Parthian period.

Another point to be considered is the characteristics of Clinkypottery. Haerinck(Haerinck[10], Young[11] and Stronach[12], have presented extensive information on this, dating this type ofpottery to the mid Parthian period, i.e. the first half of the 2 nd century B.C. The 3 rd century A.D. has been suggested as the end of the widespread use of this type of pottery. It was common in an area stretching fromGhasr-e Shirin in west Iran, through Maragheh in the northwest,andthe central plateau. Considering the diverse forms and shapes of the Clinky pottery, it is hypothesis that those objects were probably used over a longer era.

The morphological analysis of the Clinky pottery also shows a certain typewith an angular (boatshaped) body. Similar pottery pieces are available from the Neo-Assyrian era, Iron Age III, and the Achaemenidperiod[13].Certain types of delicate pottery have also been found in northwest Iran, particularly in Qalaichi and Ziwiye that resemble the Clinky pottery of west Iran in terms of form and style[14].

The influence of local and regional styles on the structure of Parthianculturedeserves discussion. In addition to pottery with specific local features found across remote mountains of the western part of Central Zagros, only imitations of common Parthian period styles are seen in this area. The fabric of the pottery in the remote mountainous areas of west Zagros is coarse, and there is no sign of Clinkyorpainted pottery at the heart of the mountains. Except for a few pieces buried beside the jartomb cemeteries of that era, there are no pottery items in the Salas-e Babajani, Paveh, and Marivan, which were highly influenced by the jartomb burial culture. Analysis of the pottery reveals a logical relationship between the finds from Marivan and the jartomb cemeteries of Germiof Moghan[15].

As for the influence of local and regional styles, evidencesuggests independent artistic styles for the Parthian times in Central Zagros. In ancient times, Southwest Asia situated on the border between the East and West, was influenced to a small extent by the Hellenistic and Roman worlds, but there is no evidence of such influence in the Central Zagros.

\subsection{The Settlement Patterns and Communication Links}

Settlement pattern is defined as the distribution of human activities within a landscape and the relationship between these activities and the natural prospect as well as social environment[16]. In this research, three factors determine the settlement system, and three modelsare based on them. These factors are the exchange of goods, transportation, and administrative activity. Explaining these models in a study can reveal the structures of societies in different periods. Covering the first and the second factors, is the reason which makes Central Zagros prominent in studies. This region has been a major route since prehistory, through the Achaemenid period, and up to later periods; and evidences from surviving historical texts indicate that it served as the most important area linking the East to the West.Its broad valleys and, less often, its plains were crossed by merchants and sometimes troops. It is important thattrade should not be considered only in economic terms, as it also contributes to the spread of culture. Considering the question rose earlier and concerning the distribution of settlement patterns in this region, it is worth mentioning that despite the territorial diversity of the Central Zagros, the survey included all regional areas and attempts were made to analyze those patterns using the data from all the settlements[1].

\subsubsection{The Sizes of the Sites}

Nearly 90 percent of the 340 sampled Parthian sites were less than 1 hectare. An interesting point is that many of these grounds had only one settlement period. A weak settlement period was seen in most of the mountainous areas, whose sole function seems to be their use for nomadic tribes. The areas and hills inside the plains follow anexpected chronological order, and several areas inside the plains cover more than 1 hectare.

\subsubsection{The Functions of the Areas and the Status of the Settlements}

- This research aims to provide an accurate accountofthe condition of the Central Zagros during the Parthian period so that the following objectives are achieved:

- The accurate identification of the settlement patterns, hubs, routes, and natural resources

- An understandingof the present day situation and its relationship with ancient sites

- An understanding of the economic condition of the region through specifying the level of investment in the roads and public buildings

- An assessment of the regional security during the Parthian period

- An assessment of the territorial influences on the local culture

- Conducting researches on the typology of the pottery 


\subsubsection{The Cemeteries}

An interesting point is that almost all Parthian cemeteries are located in mountainous areas that are difficult to negotiate, in the western side of the Central Zagros, and in the valleys dominating the eastern plains. A very interesting area of archeological research in this region is the extreme density of cemeteries, particularly jartomb cemeteries, in the Marivan, Javanroud and Paveh regions and the Salas-e Babajani.

\subsubsection{The Strategic Spots}

The remains of several forts and military zones were identified alongside the main road starting fromSarPoleZahab, ending at Hamadan. Such Fortresses and military zones arenot identified in areas far from the main road, suggesting they were constructed

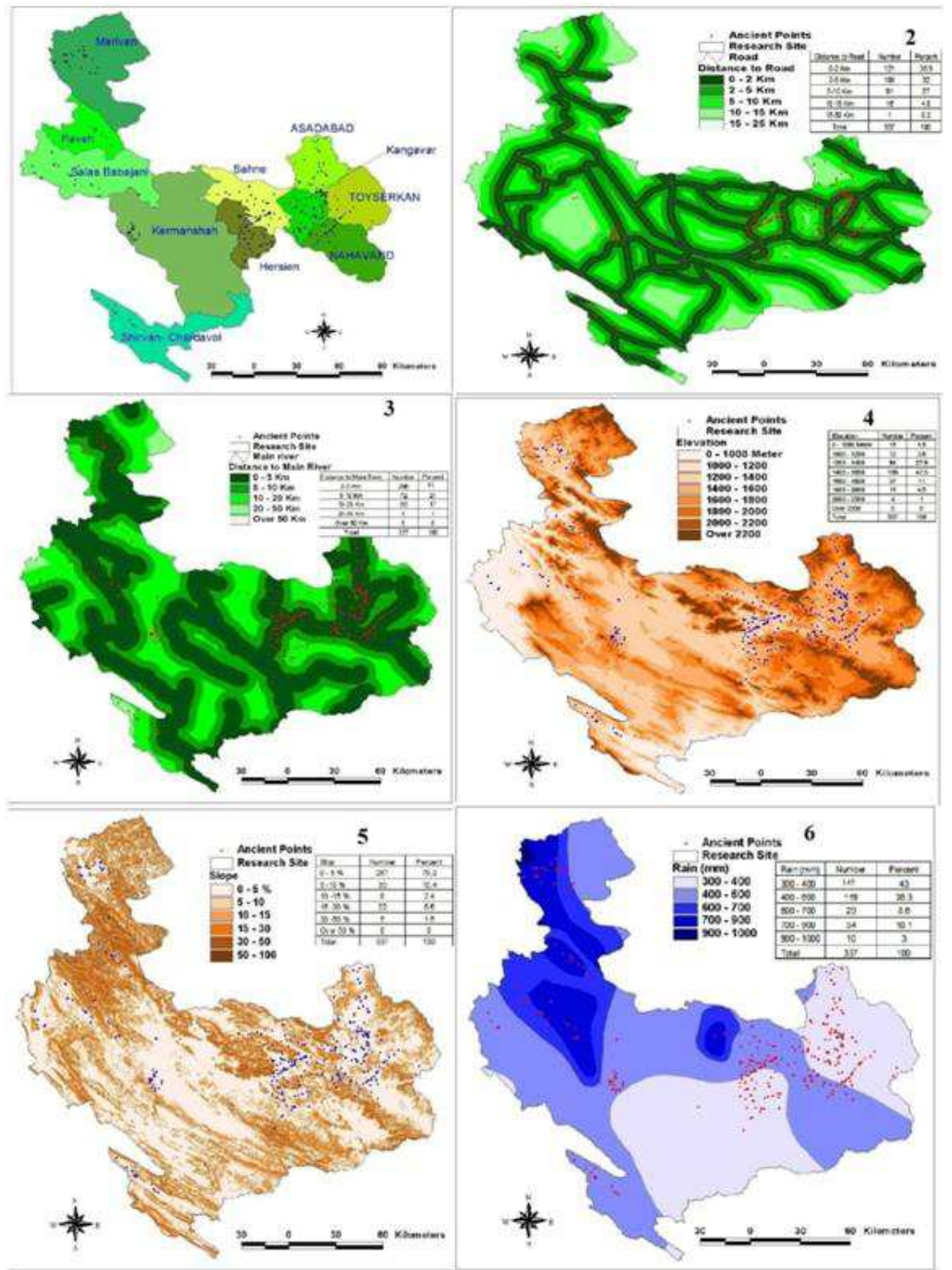

Fig 2. Input environmental layers: (1) distribution of Parthian site in surveyed areas (2) distance of sites to the natural connection routes (3) distance of sites to the water system (4) setting of sites on different elevations (5) setting of sites on slopes (6) site distribution in relation to annual precipitation to control major routes (which are still in use today). 


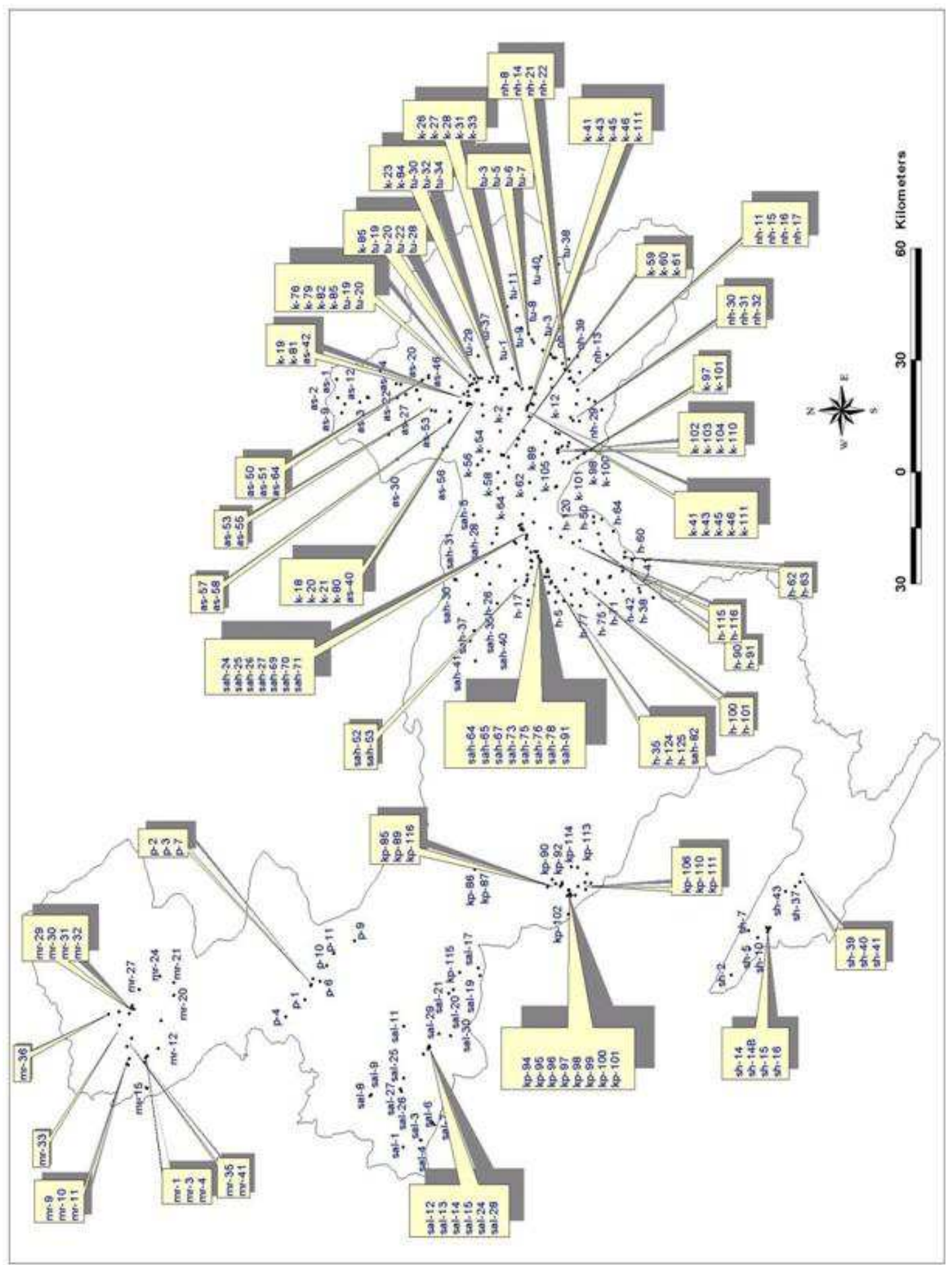

Fig 3. Digital archive of Parthian archaeological sites in the study area

\section{Analysis of the Environment}

The relationship between the settlement patterns and factors such as annual precipitation, humidity, vegetation cover, animal resources and other environmental factors were considered through use of maps[17]. Analysis revealed a significant relationship among the pottery types of the fertile agricultural plains. This is while the pottery of the western mountains of Central Zagros is quite rough, falling well beyond common standards (fig. 2).

\subsection{Analysis of the Altitude}

Another significant point is the altitudinal analysis of the areas based on GIS models. The result was that the Parthian tribes residing in the plains benefited from the 
common patterns of their preceding eras, while in the higher mountains single component settlements indicated the presence of temporary settlements at the heights.

\section{Developing a Digital Archive}

One of the achievements of this fouryear research project was the creation of a databank on the sites and areas dating back to the Parthian period (fig. 3). The archive includes:

- information on the size of the sites

- the altitude of the hills

- vegetationcover

- geographical specifics

- the type of the pottery and other artifacts

- location of ancient and new roads

- accurate records, photos and maps of the hills.

\section{Conclusions}

A topographical survey of eleven townships in the Central Zagros was carried out in order to identify the settlement patterns and investigate the condition of the Parthian period sites in this region. In total 623 areas were identified of which 340 hills and areas were dated to the Parthian period. One of the aims of this research was to identify the relationship between the Parthian period and its preceding and following eras, in order to achieve this, the pottery pieces recovered by the researchers were used as the main evidence.

Concerning the distribution of the settlement patterns, of the 340 siteswith Parthian pottery, it isrecognized that 99 of those sites have only one settlement period during the Parthian era, 106 of them have two periods, 74 have three periods, 39 have four periods, and only 20 have five or more periods of settlement. Analyzing such data hasgiven important information on the expansion of settlements and nomadic communities in the Parthian period as well as comparisons with the preceding and following eras; in this research a population explosion and hence shortage of basic materials, particularly for the nomadic pastoralists, is identified in the Central Zagros region. The latter caused those tribes to move, for the first time, to mountainous and uninhabited areas which were difficult to negotiate. Interestingly, historical sources suggest a tribal influx from Central Asia into some of the local areas during the Seljuk era, in the 4th and 5th centuries after Hijra. Such historical experience may have been passed on from the Parthian period to the later itinerant populations.

Analysis of the data shows that nearly onethird of the Parthian period settlements in Central Zagros had only one pattern. Statistical analysis indicates a range of newly established settlements during this period [18]. An interesting point is that these settlements were unprecedented and most of the Parthian single layer settlements had not been considered either before or after that period. The reason for this becomes clear when we examine the geographical maps.

Another important point is that out of the 340 sites studied, the Parthian settlement patterns are similar to those of the Chalcolithic and Middle and New Bronze Ages, and, on the other hand, the patterns of the Islamic middle centuries resemble those of the Parthian times. Most of the settlements of this period were small villages situated near rivers, canals and springs, and the number of the villages was remarkably larger compared to the previous period. The settlements were expanded to include cave shelters also, and this is observed at the entrances of several shelters in Hulilan. The caves were uninhabited since the pre-Paleolithic era until the Parthian period, and diagnostic pottery shardsare observed at the cave entrances and in the immediate area.

An important point concerning the distribution patterns is that most of the settlements were formed in the plains and near agricultural areas as well as pastures and sources of water to benefit from the natural resources. No agricultural field is seen in the rough mountainous terrains, and the only residents of the contemporary settlements are itinerant stockbreeders. This pattern is clearly common to the Salas-eBabajani, Paveh, Marivan, the mountains dominating Kangavar, Assadabad, Tuyserkan, and Harsinalso. Single layer settlements which can be clearly attributed to nomads may be studied and discussed only from that period.

As far as classification of the areas is concerned, there is a major problem in analyzing the settlements of the Parthian period, and that is the distribution of the data over hills and large areas. This makes it difficult to analyze and classify the sites, as most of those settlements were temporary and lacked architecture, and the pottery pieces were scattered over a vastarea.

\section{Acknowledgments}

Appreciation is offered to the Iran National Science Foundation (INSF) for a grant to collect site data which were used for this research. The authors would like to thanks all the members of the survey team for their kindly cooperation. Grateful thanks to the Cultural Heritage Organizations of Hamedan and Kermanshah that provided access to site locations.

\section{References}

[1] NIKNAMI, K. A., MOHAMMADIFAR, Y. \& M.R.SARAFF, 2007, Modeling Parthian Site Distribution Patterns in The Central Zagros Region, Western Iran, Journal of the Faculty of Literature \& Humanities, 180 (2): 93.110 [in Farsi]. 
[2] DEBEVOISE, N.C. 1934, Parthian Pottery from Seleucia on the Tigris, Ann Arbor: Michigan University Press.

[3] YOUNG, T.C., 1963, Proto-historic Western Iran: an Archeological and Historical Review, Ph.D. Thesis University of Pennsylvania.

[4] YOUNG, T.C., 1967, The Iranian Migration into the Zagros, Iran $\mathrm{V}: 11.34$.

[5] YOUNG, T.C., \& LEVINE, L., 1974, Excavation of the Godin Project: Second Progress Report, The Royal Ontario Museum,Canada.

[6] LEVINE, L. 1987, The Iron Age, in: F. Hole (ed.) The Archaeology of Western Iran. Settlement and society from Prehistory to the Islamic Conquest, Washington, D.C.: Smithsonian Institution Press, pp. 229.250.

[7] YOUNG, T.C., 1985. The Chronology of the Late Third and Second Millennia in Central Western Iran as Seen from Godin Tepe, American Journal of Archaeology 89: 287.290.

[8] YOUNG, T.C., 1975, Kangavar Valley Survey, Iran 13: 191.193.

[9] MOHAMMADIFAR, Y., 2007, Archaeological Survey of Sahneh County, Journal of the Iranian Studies of Kerman University, 11: 173.194, (in Farsi).

[10] HAERINCK, E. 1991, Ceramic, Encyclopedia Iranica, USA, Vol. V, Fasc. 3, pp. 304.307.
[11] YOUNG, T.C., 1965, Survey in Western Iran 1961 Journal of Near Eastern studies 25 (A): 228.239.

[12] STRONACH, D., 1969, Excavation at TepeNush-i Jan, Iran, VII: 1.20 .

[13] STRONACH, D., 1978, Pasargadae. A Report on the Excavations Conducted by the British Institute of Persian Studies from 1961 to 1963 , 1978, Oxford.

[14] MOLLAZADEH, K., 2008, The Pottery from the Mannean Site of Qalaichi, Bukan (NWIran), Iranica Antiqua 43: 107.125.

[15] MOHAMMADIFAR, Y, \& M.R. SARRAF, 2006, A Glance at Burial Rites in Pithos of Arsacids Era Located in Western Region of Central Zagros, The Journal of Humanities, 13 (3): 51.62

[16] SCHREIBER, 1996, Settlement Pattern Analysis, The Oxford Companion.

[17] MOHAMMADIFAR, Y., 2008, The Survey and Analysis of Parthian Relic and Settlement in Central Zagros, Ph. D. Thesis, Department of Archaeology, TarbiatModares University, Tehran, [in Farsi).

[18] NIKNAMI, K. A., IRANDOUST H and TAHMASEBI A. 2012, Environmental and Cultural Factors Influencing Parthian Archaeological Site Distribution in the Sarfirouzabad Plain of Kermanshah, Northwest of Iran, International Journal of Geosciences (in press). 